due to the untiring efforts of Basaglia and his group. after collecting half a million signatures pressing for a change. the Italian parliament passed the Mental Treatment Act. also known as the Law No 180. which underlined the desirability of the closure of psychiatric hospitals and that steps were to be taken to establish community mental health centres. There were to be no more than 15 beds per 200.000 of the general population. Such a radical change also ensured that no staff member would be made redundant because of the reform. It emphasized that the activities of prevention. therapy and rehabilitation were to be carried out from a non-hospital base. The change was therefore total. and it had to be if it was to work.

During their two-week stay here, our Italian visitors met social workers. mental health workers. psychiatric staff. hospital administrators. patients, voluntary organizations, the probation and after-care services. politicians, students and other interested groups. It was interesting to see so much enthusiasm from the non-psychiatric public and it clearly showed that there is perhaps a large, silent body of people concerned about mental health. It showed that many were interested but wary about the way professionals worked. Many questioned the control and power that psychiatrists had over the vulnerable and emotionally disturbed.

The Italians were critical about the lack of integration of the various services and their tendency to serve the professionals' needs rather than the patients'. Their approach centered on a well-developed crisis intervention arrangement. manned by nurses. doctors, psychologists and social workers to provide a quick and efficient service for their patients to be seen with their families in the social environment in which they live. and to attempt to resolve the problem without taking the patient away from the troubled situation. Rarely, there would be a case to remove the patient and for this they have no more than 15 beds per 200,000 of the general population. either in a general hospital or in a mental health centre. It was unusual for all the 15 beds to be used. This also forced a considerably greater involvement in human relationships by those concerned. In the case of violent patients, or if a crime was committed, it would be a problem for the law and. if concurrently there was a need for psychiatric treatment. it was accordingly provided. This emphasized the difference between illness and responsibility. It is interesting that our visitors commented that this affected the presenting symptomatology of previously violent patients.

The community health centres are open for anyone to drop in without the need for a general practitioner referral. and they are seen by whoever is available. Little emphasis is put on drug treatments. The community health centre has a fairly strict and small catchment area so that it becomes part of the small community it serves. It involves itself with the town's housing. education. welfare. planning. employment and other agencies. In this way it represents the mentally ill as well as the society they belong to. thus reducing fear and suspicion on both sides. The needs of the elderly demented population were seen as a separate issue. that is dealt with by a service of its own.

There has been considerable criticism in Italy of this system. Accepting Basaglia's ideas would mean questioning some very fundamental issues in psychiatry. It would mean paying greater emphasis to the person, his world. and the way society behaves rather than the traditional view that psychiatry is part of medicine and biochemistry as a means of solving problems that are essentially human. Such a system shifts a considerable part of the responsibility to the patient, and more so to the family who may be ill-equipped to bear the burden. On the other hand. this system provides early attention and care and encourages a greater involvement in the patients' lives and their families. Direct access to the community centres without having to go through the general practitioner means a quicker referral. Huge hospitals, with their administration and related staff. then do not need to be maintained and occupational therapy services can be reduced to a small scale. Opponents of this system claim that it has not worked out as they hoped, and that many of the old hospitals still exist, understaffed and poorly maintained. with a lack of community resources. A lack of statistics makes it difficult to assess change. and information is mainly anecdotal and varies greatly from place to place. but there is little doubt that, in principle. the movement is a more humane one. Even our enthusiastic Italian visitors maintained that it would be wrong for them to say that their system was without fault and theirs was only a necessary step to the next stage.

\section{University of Oxford, Neurosciences Course}

An intensive course in neurosciences will be held in the University Department of Human Anatomy from 16 to 20 September 1985. This annual course provides an intensive up-to-date review of the neurosciences for physicians. psychiatrists. psychologists and others interested in this field. The basic sciences component is suitable for those preparing for the MRCPsych and other examinatioins. Residential accommodation will be available. Enquiries: Director of Postgraduate Medical Education and Training. Medical School Offices. Level 3. John Radcliffe Hospital. Headington. Oxford OX3 9DU. 